\title{
Pengaruh Religiusitas, Agreeableness, dan Usia Terhadap Perilaku Prososial Remaja
}

\author{
Ika Maya Widiastuti \\ Psychology Department \\ UIN Syarif Hidayatullah Jakarta \\ Jakarta 11480, Indonesia \\ ikamayawidiastuti@mhs.uinjkt.ac.id
}

Correspondence: ikamayawidiastuti@mhs.uinjkt.ac.id

\begin{abstract}
This study aims to examine the effect of religiosity, agreeableness, and age on adolescence's prosocial behavior. This study selected the sample of 296 student, using a purposive sampling technique. The data collection used modification scale of Prosocialness Scale, Muslim Daily Religiosity Assessment Scale (MUDRAS), and International Personality Item Pool-Big Five Factors Model-50 (IPIP-BFM-50). Multiple regression and Confirmatory Factor Analysis (CFA) were performed to analyze the data. The finding showed there is a significant influence of religiosity, agreeableness, and age on prosocial behavior.
\end{abstract}

Keyword: Prosocial Behavior; Religiosity; Agreeableness; Age

\begin{abstract}
ABSTRAK
Penelitian ini bertujuan untuk menguji pengaruh religiusitas, agreeableness, dan usia terhadap perilaku prososial remaja. Pengambilan sampel dalam penelitian ini menggunakan teknik purposive sampling, dengan total sampel 296 orang. Skala yang digunakan untuk pengumpulan data merupakan modifikasi dari Prosocialness Scale, Muslim Daily Religiosity Assessment Scale (MUDRAS), dan International Personality Item Pool-Big Five Factors Model-50 (IPIP-BFM-50). Analisis data menggunakan multiple regression dan Confirmatory Factor Analysis (CFA). Hasil uji hipotesis menunjukkan bahwa terdapat pengaruh yang signifikan religiusitas, agreeableness, dan usia terhadap perilaku prososial.
\end{abstract}

Kata Kunci: Perilaku Prososial; Religiusitas; Agreeableness; Usia

\section{PENDAHULUAN}

Masa remaja merupakan masa peralihan dari fase anak-anak menuju dewasa, di mana banyak perubahan yang berkembang pesat pada diri mereka, baik dari segi fisik, perilaku, maupun sikap (Santrock, 2007). Salah satu hal yang sering disoroti dari remaja adalah munculnya perilaku yang tidak sesuai dengan norma sosial, seperti perkelahian, bolos sekolah, dan perundungan.

Dalam studi literatur ditemukan adanya kenakalan remaja, baik berupa kenakalan ringan seperti bolos sekolah dan merokok; maupun kenakalan yang mengganggu ketentraman dan keamanan orang lain berupa meminta sesuatu secara paksa dan perkelahian Azhari (2019). Studi pendahuluan yang telah dilakukan penulis melalui pengamatan langsung dan wawancara juga menunjukkan bahwa dikalangan mereka bolos sekolah, acuh tak acuh terhadap teman, kurang peduli terhadap kebersihan lingkungan, merokok, dan bahkan melakukan 
perundungan. Dari pemaparan tersebut maka dapat dikatakan bahwa mempromosikan perilaku prososial di kalangan remaja menjadi sesuatu yang penting untuk dilakukan. Kualitas interaksi antar individu maupun antar kelompok dapat ditentukan dengan ada tidaknya perilaku prososial diantara mereka. Karena perilaku sosial, sebagai perilaku normatif, menjadi kunci pokok seseorang dapat diterima dalam lingkungan sosialnya (Juntilla et al. dalam Rahajeng \& Wigati, 2018).

Perilaku prososial dapat didefinisikan sebagai perilaku sukarela yang dimaksudkan untuk memberi manfaat kepada orang lain (Eisenberg et al., 2015). Perilaku ini dapat berupa tindakan berbagi (sharing), menolong (helping), maupun menghibur (comforting). Perilaku prososial yang sudah dibiasakan sejak masa remaja dapat mendorong individu untuk mengikuti lintasan yang menguntungkan menuju masa-masa dewasa kelak (Hardy \& Carlo, 2011). Di samping itu, perilaku prososial dapat mencegah munculnya perilaku agresif dan meningkatkan prestasi akademik selama masa remaja (Caprara et al., 2014).

Perilaku prososial individu dapat muncul oleh berbagai faktor, internal maupun eksternal. Faktor internal yang mempengaruhi perilaku prososial diantaranya moral identity (Gotowiec \& van Mastrigt, 2019; Guo et al., 2019), personality (Martin-Raugh et al., 2016; Reich et al., 2019), religiosity (Einolf, 2013; French et al., 2013; Kaur, 2020), intelligence (Guo et al., 2019), dan usia (Güroglu et al., 2014; Van der Graaff et al., 2018). Adapun faktor eksternal yang mempengaruhi di antaranya adalah social support (Hipson \& Séguin, 2015; Lai et al., 2015), parenting style (Clark et al., 2015), dan peer influence (Van Hoorn et al., 2016).

Faktor internal dalam penelitian ini akan difokuskan pada religiusitas, agreeableness personality, dan usia. Pertama, religiusitas, yakni komitmen seseorang untuk meninggalkan perbuatan yang dilarang, melaksanakan apa yang diperintahkan, dan melakukan ibadah fisik kepada Tuhannya (Olufadi, 2017). Religiusitas mempengaruhi perilaku prososial karena pada dasarnya setiap umat dianjurkan oleh agamanya untuk melakukan kebaikan, bahkan disebutkan bahwa sebaik-baik manusia adalah mereka yang bermanfaat untuk yang lainnya. Hal ini selaras dengan penelitian yang dilakukan French et al. (2013)bahwa semakin tinggi religiusitas remaja, maka dia akan lebih mudah untuk berperilaku prososial. Religiusitas menjadi salah satu faktor yang penting untuk dilihat pengaruhnya terhadap perilaku prososial terutama di lingkungan dengan budaya religius yang tinggi, dan pesantren menjadi salah satu lingkungan yang memenuhi kriteria tersebut.

Faktor internal kedua yang mempengaruhi perilaku prososial adalah personality. Personality adalah abstraksi tingkah laku yang menentukan pola interaksi dengan ligkungannya (McKenna, 2000). Dalam penelitian ini difokuskan pada agreeableness yang merupakan salah satu dimensi dari bigfive personality trait. Agreeableness merupakan kepribadian yang tampil dalam bentuk sifat ramah, baik hati, dapat dipercaya, kooperatif, tidak egois, dapat meyetujui orang lain, dapat dipercaya, dan dermawan (Goldberg, 1992). Individu dengan kepribadian agreeableness yang tinggi lebih kooperatif sehingga mengurangi perpecahan, dengan demikian perilaku prososial akan lebih mudah terwujud. Hal ini selaras dengan penelitian yang dilakukan oleh Reich et al., (2019) bahwa agreeableness memiliki pengaruh yang signifikan terhadap perilaku prososial, artinya semakin tinggi agreeableness individu maka semakin sering berperilaku prososial. Adapun menurut Martin-Raugh et al., (2016) pengaruh agreeableness terhadap perilaku prososial bukan merupakan pengaruh secara langsung yakni dimediasi oleh pengetahuan tentang bagaimana berperilaku yang baik dan situasi yang menantang.

Selanjutnya yaitu usia, semakin bertambahnya usia seseorang, maka ia akan lebih matang secara emosional, sehingga lebih mudah menghindari tindakan yang merugikan orang lain. Van der Graaff et al. (2018) longitudinal research on its development and predictors is still sparse. This 6-wave longitudinal study investigated the development of prosocial behavior across adolescence, and examined longitudinal associations with perspective taking and empathic concern. Participants were 497 adolescents (Mage $11=13.03$ years, $43 \%$ girls dalam penelitiannya menyebutkan bahwa perilaku prososial remaja meningkat antar usia 16-17 tahun. Lain halnya dengan Güroglu et al. (2014) berpengaruhnya usia terhadap perilaku prososial ditentukan oleh hubungan individu dengan teman sebaya. Ketika hubungan pertemanan mereka baik, maka perilaku prososialnya tinggi, begitu sebaliknya. Penelitian ini bertujuan untuk mengetahui apakah terdapat pengaruh yang signifikan dari religiusitas, agreeableness, dan usia terhadap perilaku prososial. 


\section{METODE PENELITIAN}

Jumlah subjek dalam penelitian ini adalah 296 responden ( $\mathrm{P}=182, \mathrm{~L}=114)$ yang merupakan remaja awal dan pertengahan, yakni berumur 13-18 tahun. Subjek dipilih dengan cara purposive sampling dengan kriteria remaja jenjang sekolah menengah pertama atau sederajat dan sekolah menengah atas atau sederajat yang merupakan santri mukim dan aktif di salah satu pesantren di Kabupaten Ponorogo. Pengumpulan data menggunakan kuesioner (selfreported) dengan skala perilaku prososial, religiusitas, agreeableness, dan dukungan sosial dengan skala Likert-4 poin. Validitas konstruk diuji dengan Confirmatory Factor Analysis (CFA) ( $\mathrm{p}>0.05, \mathrm{t}>1.96)$ menggunakan software Lisrel 8.70

Pengukuran Perilaku prososial dilakukan dengan menggunakan modifikasi dari Prosocialness Scale yang dikembangkan oleh Caprara et al. (2005) die authors proposed a novel self-report 16-item scale for assessing individual differences in adult prosocialness and tested its measurement properties by employing an item response theory (IRT, terdiri dari 15 item dengan aspek helping, sharing, dan comforting. Contoh item dari skala ini yakni, "saya sering membantu keluarga yang kesulitan", "saya bersedia membagi pengetahuan dan kemampuan saya untuk orang lain", "saya selalu tergerak untuk menghibur teman yang sedih". Model fit dari skala perilaku prososial dengan chi-square $=74.78, \mathrm{df}=57, \mathrm{P}$-value $=0.05715, \mathrm{RMSEA}=0.033$

Skala religiusitas terdiri dari 20 item dari Muslim Daily Religiosity Assessment Scale (MUDRAS) yang dikembangkan oleh (Olufadi, 2017). Alat ukur ini terdiri dari dimensi sinful act, recommended act, dan engaging in bodily worship. MUDRAS merupakan skala religiusitas yang indikatornya terkait secara langsung dengan indikator-indikator agama Islam. Contoh item dari skala religiusitas, "memberikan keterangan palsu", "menepati janji", dan "berapa kali anda sholat tepat pada awal waktu?" Model fit dari religiusitas yakni chi-square $=26.51$, $\mathrm{df}=18, \mathrm{P}$-value $=0.08873, \mathrm{RMSEA}=0.040$ untuk aspek sinful act , chi-square $=10.96, \mathrm{df}=8, \mathrm{P}$-value $=0.20424$, RMSEA $=0.035$ untuk recommended act, dan chi-square $=2.86, \mathrm{df}=2, \mathrm{P}$-value $=0.23966$, RMSEA $=0.038$ untuk engaging in bodily worship.

Skala agreeableness terdiri dari 8 item yang merupakan adaptasi subsakal agreeableness dari International Personality Item Pool Big Five Factors Model-50 (IPIP-BFM-50). Skala ini dikembangkan oleh Goldberg (1992). Contoh dari item ini adalah, "memahami perasaan orang lain", peduli dengan orang lain". Skala agreeableness ditemukan model fit dengan chi-square $=33.53, \mathrm{df}=23, \mathrm{P}$-value $=0.07226, \mathrm{RMSEA}=0.039$.

Analisis data dalam penelitian ini menggunakan multiple regression untuk menguji hipotesis penelitian mengenai pengaruh religiusitas, agreeableness, dan usia terhadap perilaku prososial yang dimoderasi oleh dukungan sosial. Analisis data menggunakan software SPSS versi 20.0.

\section{HASIL DAN PEMBAHASAN}

Hipotesis pertama yang diuji adalah ada pengaruh yang signifikan religiusitas, agreeableness, dan usia terhadap perilaku prososial. Hal-hal yang digunakan sebagai acuan analisis yaitu pertama, besaran R Square $\left(\mathrm{R}^{2}\right)$ untuk mengetahui berapa persen perilaku prososial dijelaskan oleh religiusitas, agreeableness, dan usia. Kedua, tabel anova (hasil uji F) untuk mengetahui apakah semua variabel independen secara bersama-sama memiliki pengaruh yang signifikan terhadap variabel dependen. Selanjutnya, dilihat signifikan atau tidaknya koefisien regresi dari masing-masing variabel independen terhadap perilaku prososial (uji t). 
Tabel 1. Model Summary Analisis Regresi Semua IV terhadap DV

\begin{tabular}{ccccc}
\hline Model & $\mathrm{R}$ & R Square & Adjusted R Square & Std. Error of the Estimate \\
\hline 1 & $0,658^{\mathrm{a}}$ & 0,432 & 0,423 & 6,96968 \\
\hline
\end{tabular}

a. Predictors: (Constant), Usia, Worship, Agreeable, Sinful, Recommended

Tabel 2. Anova Pengaruh Keseluruhan IV terhadap DV

\begin{tabular}{clccccc}
\hline & Model & Sum of Squares & df & Mean Square & F & Sig. \\
\hline \multirow{2}{*}{1} & Regression & 10733,066 & 5 & & 44,190 & $0,000^{\mathrm{b}}$ \\
& Residual & 14087,178 & 290 & 2146,613 & & \\
& Total & 24820,244 & 295 & 48,576 & & \\
\hline
\end{tabular}

a. Dependent Variable: Prososial

b. Predictors: (Constant), Usia, Worship, Agreeable, Sinful, Recommended

Tabel 3. Koefisien Regresi IV terhadap DV

\begin{tabular}{lccccc}
\hline \multirow{2}{*}{ Model } & \multicolumn{2}{c}{ Unstandardized Coefficients } & $\begin{array}{c}\text { Standardized } \\
\text { Coefficients }\end{array}$ & $\mathrm{t}$ & Sig. \\
\cline { 2 - 4 } & $\mathrm{B}$ & Std. Error & Beta & & \\
\hline (Constant) & 4.846 & 3.733 & & 1,298 & 0,195 \\
Sinful & $-0,012$ & 0,049 & $-0,011$ & $-0,237$ & 0,813 \\
Recommended & 0,072 & 0,053 & 0,068 & 1,380 & 0,169 \\
Worship* & 0,210 & 0,062 & 0,166 & 3,399 & 0,001 \\
Agreeable* & 0,578 & 0,050 & 0,553 & 11,488 & 0,000 \\
Usia* & 1,972 & 0,851 & 0,105 & 2,317 & 0,021 \\
\hline
\end{tabular}

Dependent Variable: Prososial

(*) signifikan

Dalam uji R square didapatkan hasil 0.432 (tabel 1). Artinya, proporsi varian dari perilaku prososial dijelaskan oleh religiusitas, agreeableness, dan usia sebesar $43.2 \%$, sisanya oleh variabel lain di luar penelitian ini. Kemudian berdasarkan hasil uji $\mathrm{F}$ yang telah dilakukan dihasilkan nilai $\mathrm{F}$ hitung sebesar 44.190 (tabel 2) dengan signifikansi 0.00 ( $\mathrm{sig}<0.05)$. Artinya secara bersama-sama ada pengaruh yang signifikan dari variabel religiusitas, agreeableness, dan usia terhadap perilaku prososial. Kemudian dilihat dari koefisien regresi dari masing-masing variabel independen, terdapat terdapat tiga variabel yang signifikan, yakni engaging in bodily worship dari aspek religiusitas, agreeableness, dan usia (tabel 3).

\section{Diskusi}

Berdasarkan hasil uji hipotesis ditemukan bahwa terdapat pengaruh religiusitas, agreeableness, dan usia terhadap perilaku prososial. Adapun hasil koefisien regresi dari masing-masing variabel independen yang mempengaruhi perilaku prososial secara signifikan adalah dimensi engaging in bodily worship, agreeableness, dan usia.

Dimensi engaging in bodily worship berpengaruh secara signifikan terhadap perilaku prososial dengan arah yang positif, artinya semakin tinggi nilai engaging in bodily worship yang dimiliki individu maka semakin tinggi perilaku prososialnya. Engaging in bodily worship merupakan tindakan beribadah seperti menjalankan sholat. Dimana esensi sholat adalah mampu menjauhkan diri dari perbuatan keji dan munkar, dan sebagai tolak ukur apakah sholat individu sudah benar adalah semakin baik akhlaknya, ditandai dengan tergeraknya hati untuk membantu orang yang membutuhkan, memiliki keprihatinan, dan peduli terhadap orang lain (Istianah, 2015).

Selanjutnya variabel agreeableness berpengaruh secara signifikan terhadap perilaku prososial dengan arah yang positif, artinya semakin tinggi nilai agreeableness yang dimiliki individu maka semakin tinggi perilaku prososialnya. Agreeableness merupakan kepribadian pada individu yang ditampilkan dalam sifat penuh kasih sayang, ramah, suka bekerjasama atau kooperatif, tidak egois, bersedia menyetujui, dapat dipercaya, dan murah hati (Goldberg, 1992). Hal tersebut sebagaimana penelitian yang dilakukan oleh Reich et al. (2019) yang menyatakan bahwa agreeableness secara signifikan berpengaruh terhadap perilaku prososial.

Selanjutnya dimensi sinful act dari religiusitas tidak berpengaruh secara signifikan terhadap perilaku prososial. Dalam penelitian ini meskipun skor sinful act dominan tinggi, yang artinya lebih banyak individu yang menghindari tindakan yang dilarang agama, namun perbedaan hasil kategori rendah dan tinggi dari dimensi tersebut sangatlah tipis, yakni hanya selisih satu orang. Menurut Olufadi (2017) sinful act diantaranya ditandai 
dengan bertindak curang, memberikan keterangan palsu, mengkonsumsi barang haram, berhianat, memfitnah orang lain, berprasangka buruk terhadap orang lain, dan mengganggu ketentraman orang lain. Dengan demikian, individu yang sering melakukan sinful act akan semakin sulit untuk berperilaku prososial.

Kemudian dimensi recommended act tidak berpengaruh secara signifikan terhadap perilaku prososial. Dalam penelitian ini didapati bahwa skor recommended act responden cenderung rendah. Padahal recommended act adalah melakukan kebaikan terhadap orang lain, berkata jujur, berbakti terhadap orang tua, menepati janji, dan mengajak orang lain berbuat kebaikan (Olufadi, 2017).

\section{KESIMPULAN}

Berdasarkan hasil uji hipotesis dapat disimpulkan bahwa terdapat pengaruh dari religiusitas, agreeableness, dan usia terhadap perilaku prososial. Selanjutnya, hasil uji hipotesis dari signifikansi keseluruhan variabel independen terhadap perilaku prososial, yang memiliki pengaruh signifikan adalah dimensi engaging in bodily worship dari variabel religiusitas, agreeableness, usia.

Penulis dapat mengajukan beberapa saran untuk penelitian selanjutnya terkait topik ini. Hasil penelitian ini menunjukkan bahwa proporsi varians dari perilaku prososial yang dijelaskan oleh variabel religiusitas, agreeableness, dan usia sebesar $43.2 \%$, sehingga diperlukan penelitian lanjutan untuk meneliti variabel lain yang mempengaruhi perilaku prososial, diantaranya: moral identity, empathy, intelligence, psychological distress, religious priming concepts, emotional intelligence, sympathy, prosocial knowledge, personality, interpersonal trust, peer influence, burnout, gratitude, self-esteem, optimism, parenting style, parental warm, social class, dan social anxiety.

\section{DAFTAR PUSTAKA}

Azhari. (2019). Peran pondok pesantren dalam menanggulangi kenakalan remaja. Al-Bahtsu, 4(1), 42-54.

Caprara, G. V., Kanacri, B. P. L., Gerbino, M., Zuffianò, A., Alessandri, G., Vecchio, G., Caprara, E., Pastorelli, C., $\&$ Bridglall, B. (2014). Positive effects of promoting prosocial behavior in early adolescence: Evidence from a school-based interventio. International Journal of Behavioral Development, 38(4), 386-396. https://doi.org/10.1177/0165025414531464

Caprara, G. V., Steca, P., Zelli, A., \& Capanna, C. (2005). A New scale for measuring adults' prosocialnes. European Journal of Psychological Assessment, 21(2), 77-89. https://doi.org/10.1027/1015-5759.21.2.77

Clark, C. M., Dahlen, E. R., \& Nicholson, B. C. (2015). The role of parenting in relational aggression and prosocial behavior among emerging adults. Journal of Aggression, Maltreatment and Trauma, 24(2), 185 202. https://doi.org/10.1080/10926771.2015.1002653

Einolf, C. J. (2013). Daily spiritual experiences and prosocial behavior. Social Indicators Research, 110(1), 7187. https://doi.org/10.1007/s11205-011-9917-3

Eisenberg, N., Spinrad, T. L., \& Knafo-Noam, A. (2015). Prosocial Development. In R. M. Lerner (Ed.), Handbook of Child Psychology and Developmental Science (7th editio, pp. 1-47). John Wiley \& Sons, Inc. https://doi.org/10.1111/j.1469-7610.1994.tb01132.x

French, D. C., Eisenberg, N., Sallquist, J., Purwono, U., Lu, T., \& Christ, S. (2013). Parent-adolescent relationships, religiosity, and the social adjustment of indonesian muslim adolescents. Journal of Family Psychology, 27(3), 421-430. https://doi.org/10.1037/a0032858

Goldberg, L. R. (1992). The development of makers of the big-five factor structure. Psyhological Assessment, $4(1), 26-42$.

Gotowiec, S., \& van Mastrigt, S. (2019). Having versus doing: The roles of moral identity internalization and symbolization for prosocial behaviors. Journal of Social Psychology, 159(1), 75-91. https://doi.org/10 $.1080 / 00224545.2018 .1454394$ 
Guo, Q., Sun, P., Cai, M., Zhang, X., \& Song, K. (2019). Why are smarter individuals more prosocial? A study on the mediating roles of empathy and moral identity. Intelligence, 75(July), 1-8. https://doi.org/10.1016/j. intell.2019.02.006

Güroglu, B., Bos, W. van den, \& Crone, E. A. (2014). Sharing and giving across adolescence: An experimental study examining the development of prosocial behavior. Frontiers in Psychology, 5(APR), 1-13. https:// doi.org/10.3389/fpsyg.2014.00291

Hardy, S. A., \& Carlo, G. (2011). Moral identity: What is it, how does it develop, and is it linked to moral action? Child Development Perspectives, 5(3), 212-218. https://doi.org/10.1111/j.1750-8606.2011.00189.x

Hipson, W. E., \& Séguin, D. G. (2015). Is good fit related to good behaviour? Goodness of fit between daycare teacher-child relationships, temperament, and prosocial behaviour. Early Child Development and Care, 186(5), 785-798. https://doi.org/10.1080/03004430.2015.1061518

Istianah. (2015). Shalat sebagai perjalanan ruhani menuju Allah. Esoterik, 1(1), 47-64.

Kaur, S. (2020). Effect of religiosity and moral identity internalization on prosocial behaviour. Journal of Human Values, 1-13. https://doi.org/10.1177/0971685820901402

Lai, F. H. Y., Siu, A. M. H., \& Shek, D. T. L. (2015). Individual and social predictors of prosocial behavior among chinese adolescents in Hong Kong. Frontiers in Pediatrics, 3(May), 1-8. https://doi.org/10.3389/ fped.2015.00039

Malecki, C. K., \& Demaray, M. K. (2002). Measuring perceived social support: development of the child and adolescent social support scale (CASSS). Psychology in the Schools, 39(1), 1-18. https://doi.org/10.1002/ pits. 10004

Malonda, E., Llorca, A., Mesurado, B., Samper, P., \& Vicenta Mestre, M. (2019). Parents or peers? Predictors of prosocial behavior and aggression: A longitudinal study. Frontiers in Psychology, 10(OCT), 1-12. https://doi.org/10.3389/fpsyg.2019.02379

Martin-Raugh, M. P., Kell, H. J., \& Motowidlo, S. J. (2016). Prosocial knowledge mediates effect of agreeableness and emotional intelligence on prosocial behavior. Personality and Individual Differences, 90, 41-49. https://doi.org/10.1016/j.paid.2015.10.0

McKenna, E. F. (2000). Business Psychology and Organisational Behaviour: A Student's Handbook (3rd editio). Psychology Press.

Najib, Mu. A. (2018). Konsep dan implementasi pembinaan religiusitas siswa di SMA. Jurnal Tawadhu, 2(2), $556-571$.

Olufadi, Y. (2017). Muslim daily religiosity assessment scale (MUDRAS): A new instrument for muslim religiosity research and practice. Psychology of Religion and Spirituality, 9(2), 165-179. https://doi. org/10.1037/rel0000074

Padilla-Walker, L. M., Fraser, A. M., Black, B. B., \& Bean, R. A. (2015). Associations between friendship, sympathy, and prosocial behavior toward friends. Journal of Research on Adolescence, 25(1), 28-35. https:// doi.org/10.1111/jora.12108

Rahajeng, U. W., \& Wigati, T. Y. A. (2018). Perilaku prososial sebagai prediktor status teman sebaya pada remaja. Jurnal Psikologi Teori Dan Terapan, 8(2), 124. https://doi.org/10.26740/jptt.v8n2.p124-132

Reich, W. A., Sangiorgio, C., \& Young, J. (2019). Self-role integration: A person-specific predictor of life satisfaction and prosocial behavior. Journal of Psychology: Interdisciplinary and Applied, 153(6), 649-666. https://doi.org/10.1080/00223980.2019.1590297

Riska, H. A., Krisnatuti, D., \& Yuliati, L. N. (2018). Pengaruh interaksi remaja dengan keluarga dan teman serta self-esteem terhadap perilaku prososial remaja awal. Jurnal Ilmu Keluarga Dan Konsumen, 11(3), 206-218. https://doi.org/10.24156/jikk.2018.11.3.206

Santrock, J. W. (2007). Educational Psychology. McGraw-Hill Higher Education.

Van der Graaff, J., Carlo, G., Crocetti, E., Koot, H. M., \& Branje, S. (2018). Prosocial behavior in adolescence: Gender differences in development and links with empathy. Journal of Youth and Adolescence, 47(5), 
1086-1099. https://doi.org/10.1007/s10964-017-0786-1

Van Hoorn, J., van Dijk, E., Meuwese, R., Rieffe, C., \& Crone, E. A. (2016). Peer influence on prosocial behavior in adolescence. Journal of Research on Adolescence, 26(1), 90-100. https://doi.org/10.1111/jora.12173

Wentzel, K. (2015). Prosocial behaviour and schooling. Encyclopedia of Early Childhood Development, 1-5.

Zimet, G. D., Dahlem, N. W., Zimet, S. G., \& Farley, G. K. (1988). The multidimensional scale of perceived social support. Journal of Personality Assessment, 52(1), 30-41. https://doi.org/10.1207/s15327752jpa5201_2 